\title{
Nasal Rhinosporidiosis in a Nigerian Child: A Rare Clinical Entity
}

\author{
Daniel Aliyu ${ }^{1^{*}}$, Sadikku Mallami Sahabi ${ }^{2}$ \\ ${ }^{1}$ Department of Ear, Nose and Throat, Usmanu Danfodiyo University Teaching Hospital, Sokoto, Nigeria \\ ${ }^{2}$ Department of Histopathology, Usmanu Danfodiyo University Teaching Hospital, Sokoto, Nigeria \\ Email: 믹y55@gmail.com, smsahabi@yahoo.co.uk
}

Received September 19, 2013; revised October 15, 2013; accepted November 10, 2013

Copyright (C) 2014 Daniel Aliyu, Sadikku Mallami Sahabi. This is an open access article distributed under the Creative Commons Attribution License, which permits unrestricted use, distribution, and reproduction in any medium, provided the original work is properly cited. In accordance of the Creative Commons Attribution License all Copyrights (C) 2014 are reserved for SCIRP and the owner of the intellectual property Daniel Aliyu, Sadikku Mallami Sahabi. All Copyright (C) 2014 are guarded by law and by SCIRP as a guardian.

\section{ABSTRACT}

Background: Rhinosporidiosis is a rare chronic granulomatous disease characterized by polypous lesion of the mucous membrane caused by rhinosporidium seeberi which predominantly affects the mucous membrane of the Naso-pharynx, conjuctiva and palate. Rhinosporidiosis can be easily misdiagnosed as a neoplastic disease, and hence, it is necessary to educate the public and medical community about this emerging disease entity in our region. Aim: To report a rare case of nasal rhinosporidiosis in a 13-year-old male patient from Sokoto, North Western Nigeria. Case Report: A 13-year-old male Quranic child from gwadabawa village in Sokoto State, North Western Nigeria, whose parents are rice farmers, presented in the ENT clinic of Usmanu Danfodiyo University Teaching Hospital with 15-month history of intermittent epistaxis and left nasal mass noticed one month before presenting. He was examined clinically and a pinkish polypoidal mass arising from the septum and filling the left nasal cavity was seen. He subsequently had a biopsy of the mass and histopathological examination with special histochemical staining, which confirmed rhinosporidiosis. Conclusion: Rhinospridiosis is an unusual cause of nasal masses in our region and is probably a fungal disease. To the best of our knowledge, this is the first reported case in this region. This lesion largely mimics ordinary nasal polyp; therefore, it is an important possible differential diagnosis to be considered in our region when evaluating patients with nasal masses.

\section{KEYWORDS}

Rhinosporidiosis; Nasal Mass; Fungal; Child; Nigeria; Granulomatous

\section{Introduction}

Rhinosporidiosis is a chronic granulomatous disorder caused by a pathogen whose precise taxonomic classification has always been contentious called Rhinosporidium seeberi $[1,2]$. It predominantly affects the mucous membrane of the nose, nasopharynx and conjunctiva. Rhinosporidiosis occurs in human and in animals, commonly in hot tropical climates and is highly endemic in India and Sri Lanka [1-3]. Sporadic cases reported from other parts of the world such as Italy, Argentina, Brazil and in Africa [3]. Males are commonly affected with no racial predilection and the disease can be transmitted by direct contact with spores through dust, infected clothing

"Corresponding author. and swimming in stagnant water [1-3]. Even though few cases of nasal rhinosporidiosis have been reported from the eastern part of Nigeria, this disease remains exceedingly infrequent in our region. The diagnosis is established by observing the characteristic appearance of the organism in tissue biopsies (Figure 1). Treatment consists of surgical excision but a high rate of recurrence has been reported especially if surgical extirpation is not executed with extra prudence [1-4].

To the best of the author's knowledge, this is the first documented report of human nasal rhinosporidiosis from Northern Nigeria.

The aim of this report is to caution otorhinolaryngologists to have a high index of suspicion of this emerging disease entity in the management of patient with nasal 


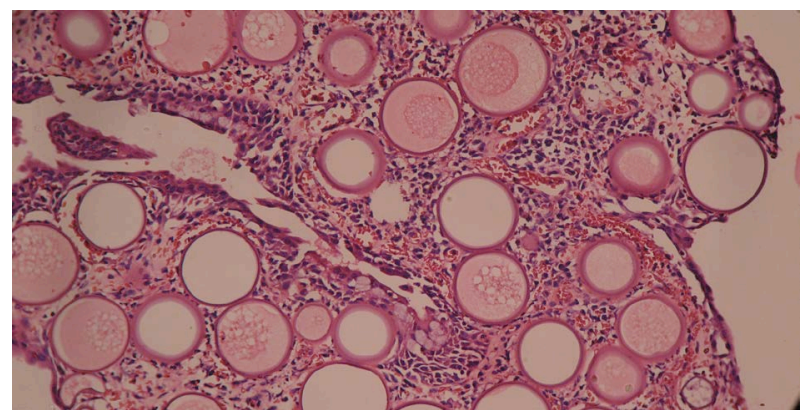

(a)

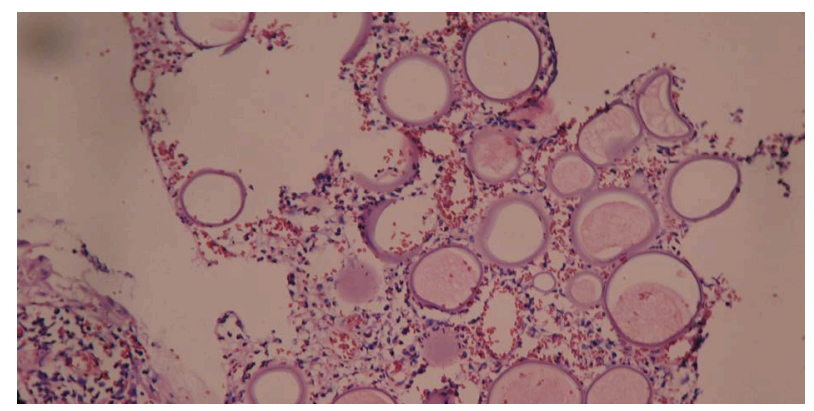

(b)

Figure 1. (a) Photomicrograph showing large Sporangium filled with spores. (b) photomicrograph showing ruptured sporangia.

mass in our region.

\section{Case Report}

A 13-year-old male Quranic school child from gwadabawa in Sokoto State, North Western Nigeria, whose parent's preoccupation is fishing, presented at the ENT clinic of Usmanu Danfodiyo University Teaching Hospital with 15-month history of intermittent epistaxis and left nasal mass noticed one month before presenting. The Nose bleeds were spontaneous and occurred initially at monthly interval since onset, but following frequent bouts of sneezing episodes, epistaxis became a daily occurrence two months prior to presentation. An estimated blood loss was 5 - 10 mls during each epsodes which resolves spontaneously. Apart from ipsilateral nasal obstructon, he reported no history of significant constitutional symptoms. There was history of swimming in the local ponds. No family history of similar illness.

Examination showed a strawberry like, fleshy polypoidal mass arising from the septum on probing and filling the left nasal cavity with associated clear mucoid rhinorrhea (Figure 2). The right nasal cavity, Nasopharynx and palate were clinically normal. The rest of the systemic and Ear, Nose and throat evaluation were unremarkable.

Hematologic investigations showed his packed cell volume to be $24 \%$ while the biochemical results were within normal limits. He was also negative to HIV I and

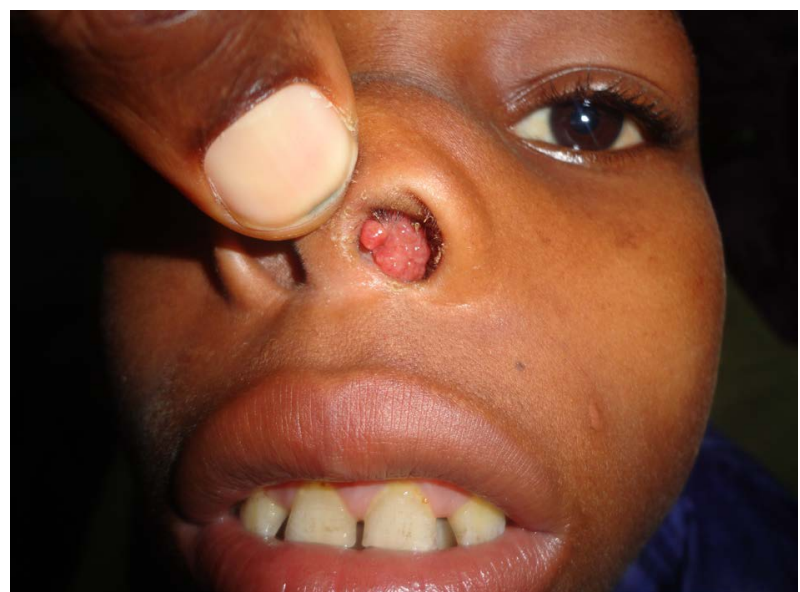

Figure 2. Strawberry like fleshy mass filling the left Nasal cavity.

II screening. Plain radiographs of the paranasal sinuses demonstrated a soft tissue shadow in the left nasal cavity but no bony or sinus involvement.

Under general anesthesia the left nasal cavity mass was completely and meticulously excised followed by electro coagulation of the lesions base. The fleshy mass was friable and measured $2 \mathrm{~cm}$ by $3 \mathrm{~cm}$ on gross examination. Histopathology of the specimen showed numerous sporangium containing spores pathognomonic of rhinosporidiosis. Postoperative periods were uneventful and no evidence of recurrence after one year of follow up.

\section{Pathology}

The haematoxylin eosin staining photomicrographs of the specimen is shown in Figure 1(a) and 1(b). The sub epithelial stroma composed of hyperplasia glands that are interspersed by numerous glandular cyst lined by thick walled sporangium filled with many spores. A few empty cysts were evident. There is dense stromal neutrophilic and lymphoplasmacytic infiltration. Features confirmed Rhinosporidiosis.

\section{Discussion}

Rhinosporidiosis is an infective diseases caused by Rhinosporidium seeberi reported to be endemic in south Asia (India and Sri Lanka). Sporadic cases have been reported from United States of America, Italy Brazil, Argentina and Africa [1-5]. This clinical entity was first discovered over a century ago from Argentina in a 19-year-old patient [3]. There are conflicting views on the taxonomic and phylogenetic positions of the causative agent $R$. seeberi but recent studies using molecular biologic phylogenetic techniques classified it with frog and amphibian pathogens in a new class, the Mesomycetozoea [6-8]. 
Its natural habitat has not been established, although there are some evidences that it is located in the ground water of natural lakes, reservoirs (artificialirrigation lakes) and in rivers [9]. We therefore believe that our patient with positive history of bathing in rivers had a very high risk of contracting this disease. Affected patient usually presents with history of nasal obstruction, sneezing, itching, postnasal discharge and occasional epistaxis.

Common sites of predilection of nasalrhinosporidiosis are the mucosal lining of the septum, inferior turbinate, vestibules, nasopharynx and nasal floor that differentiates it from ordinary nasal polyps often arising from the middle turbinate. A caution to clinicians in the evaluation of such patients $[1,2,10]$.

The definitive diagnosis of rhinosporidiosis is by histology of the biopsied tissue showing typical features pathognomonic of the disease. Surgical excision is currently the most reliable option of treatment. High incidence of local recurrences is common because of spillage of endospores on the adjacent mucosa; therefore wide excision and electrocoagulation of the base are recommended [1-4]. Medical therapy with dapsone (4, 4diaminodiphenylsulphone) as the only drug found to have some anti-rhinosporidial effect have been reported [10]. The mechanism of action of this drug is thought to arrest the maturation of the sporangia and to promote fibrosis in the stroma. Success rate were observed in the prevention of recurrence with the use of Dapsone $[2,4,10]$.

\section{Conclusion}

Rhinosporidiosis remains a rare clinical enigma in our region that is seldom diagnosed clinically and can be erroneously mistaken for a neoplastic disease. This report highlighted the fact that the disease is present in Nigeria and should be considered as a differential diagnosis of nasal mass.

\section{REFERENCES}

[1] S. N. Arsecularatne, "Recent Advances in Rhinosporidiosis and Rhinosporidium seeberi," Indian Journal of
Medical Microbiology, Vol. 20, No. 3, 2002, pp. 119-131.

[2] S. Uledi and F. Ayubu, "Human Nasal Rhinosporidiosis: A Case Report from Malawi," The Pan African Medical Journal, Vol. 9, 2011, p. 27.

[3] S. N. Arseculeratne, S. Sumathipala and N. B. Eriyagama, "Patterns of Rhinosporidiosis in Sri Lanka Comparison with International Data," The Southeast Asian Journal of Tropical Medicine and Public Health, Vol. 41, No. 1, 2010, pp. 175-191.

[4] S. Nayak, B. Acharjya, B. Devi, A. Sahoo and N. Singh, "Disseminated Cutaneous Rhinosporidiosis," Indian Journal of Dermatology, Venereology and Leprology, Vol. 73, No. 3, 2007, pp. 185-187. http://dx.doi.org/10.4103/0378-6323.32744

[5] S. N. Arseculeratne and L. Mendoza, "Rhinosporidiosis," In: W. G. Merz and R. Hay, Eds., Topley and Wilson's Microbiology and Microbial Infections, 10th Edition, ASM Press, Hodder Arnold, 2005, pp. 436-475.

[6] C. N. Pereira, I. Di Rosa, A. Fagotti, F. Simoncelli, R. Pascolini and L. Mendoza, "The Pathogen of Frogs and Amphibiocystidium ranae is a Member of the Order Dermocystida in the Class Mesomycetozoea," Journal of Clinical Microbiology, Vol. 43, No. 1, 2005, pp. 192-198. http://dx.doi.org/10.1128/JCM.43.1.192-198.2005

[7] V. Thankamani, M. S. Lipin-Dev, "Rhinosporidium seeberi Proven as a Fungus for the First Time after a Century Since Its Discovery,” Research in Biotechnology, Vol. 3, No.1, 2012, pp. 41-46.

[8] V. Thankamani and M. S. Lipin-Dev, "Demonstration of Viability and Development Stages of 10 Years old Refrigerated Culture of Rhinosporidium seeberi (?) UMH.48 First Ever Isolated from Nasal Rhinosporidiosis Yet Another Milestone, a Tribute to Guillermo Seeber," Journal of Biotechnology and Biotherapeutics-IJPI's Journal, Vol. 1, 2011, pp. 11-21.

[9] K. Kumara, S. Saranga, E. Navaratne, A. Dhammika and A. Sarath, "The Identification of the Natural Habitat of Rhinosporidium seeberi with $R$. seeberi-Specific in Situ Hybridization Probes," Journal of Infectious Diseases and Antimicrobial Agents, Vol. 25, 2008, pp. 25-32.

[10] B. C. Ezeanolue and M. A. C. Odike, "Nasal Rhinosporidiosis: A Case Report and Outcome of Therapy with Fluconazole,” Nigerian Journal of Otorhinolaryngology, Vol. 1, No. 1, 2004, pp. 22-24. 